\title{
An Article of Planning of Education Research in India
}

\author{
Sri E. Sreenivasulu \\ M.A., M.Ed., M.Phil (Ph.D.,)Principal, Sri Raghavendra College of Education Allagadda, Kurnool (Dt.) \\ A.P.India.
}

\section{Introduction}

Development of basic education has seen spectacular progress in the past decades in the Asian continent. Such developments should have far-reaching implications for national development around the world. Among others, traditional cultural values of education play a crucial role in the development of education. Such cultural values, matched by appropriate policies, could become a powerful cause for national and community commitments to education. However, the notion of basic education development, as is commonly accepted in the international community, mayor may not be compatible with traditional values in the society. The further development of basic education, and the related developments in the economy, mayor may not be in total harmony with the traditional culture. There could even be situations where further developments in education and the economy may jeopardise the aspects of the culture which used to contribute favourably to education development. The fundamental theme of reform in basic education is devolution of the finance and management of basic education to local governments and local communities. The schematic model is that primary schools (Grades 1-6) are sponsored by villages", junior secondary (Grades 7-9) by townships? and senior secondary (Grades 10-12) by counties", although there have been constant debates on the degree and level of devolution, very much because of the disparity in financial capacities among local communities.

The dominant development of the global educational system can neither be grasped by the deterministic theory of social development nor indeed understood by the monolithic modernization theory. As a matter of fact, a cursory look at the global educational development at once questions the theoretical adequacy and methodological relevance of any evolutionary approach. Nevertheless, certain stereotypes and frames of reference (Shils, 1958, pp. 614-18 Levy, 1966; Adams and Farell, 1967; Buckley, 1967), which have often enough served as dominant international models for educational planning and administration, have to be questioned if an objective assessment of the process of educational development is to be made. Underlying such stereotypes there is always an implicit assumption that there are successive stages of socio-economic growth through which all countries must necessarily pass through, no matter how diverse their historical experiences and cultural roots are. Very easily, countries are pigeon-holed and placed on continuous scales labeling them as 'less developed', 'developing' and 'developed'. Thus the problems and processes faced by societies are seen as graduating into the matured and developed stage without wittingly or unwittingly examining the assumptions of this a priori model of growth theory. The process of educational development in an international perspective is not possible if such stereotypes are taken for granted.

The structure of education as 'we see it today, has been a historical spin-off of the Industrial Revolution in the West, in particular Britain, followed by the United States and Western Europe. Each stage of educational growth was a direct response to the socio-economic requirements. of the growing factory system, socially and ideologically conditioned by the class conflict underlying capitalist production, Schools expanded as an organic part of a production-centred historical dynamic in which were reproduced the social conditions of capitalist production. Manufacturers were in need of institutions that could socialize children into the production process as distinct from those of reproduction (viz. home and family and primodial groups) and as agencies of social, symbolic and moral control. Education not only reproduced the required skills but also, at the same time, reproduced the submission to the structures of the established order which these. skills were supposed to serve. The educational process represented an ideological apparatus par excellence that reproduced submission to the ruling ideology in the children of the working classes, while at the same time it prepared the children of

\section{Planning Of Education}

Objectives and functions are now changing rapidly, since it is perceived that the best way higher education can serve society is to prepare people capable of tackling the emerging problems that beset them. These problems arc moral and ethical on the one hand and materialistic on the other, related to the basic necessities of life, namely, food and nutrition, health and sanitation, housing and shelter. These basic needs can only be satisfied through economic activity, and the education system is required to provide the necessary skills in order that these basic needs may be fulfilled. In a static, subsistence economy, higher education may only 
need to bother about mind.and character:' in an information., industrial and commercial economy, it has to cater for 'matter' as well. Clearly, higher education today cannot justify its existence by providing only academic learning for mental or spiritual development; it has to convey the necessary skills for economic, development in addition to cultural and social development, in order that natural resources might be explored and exploited, products stored and distributed, services managed, and resources conserved for future generations. Such skills would not only enable solutions to be found to present problems but also prepare young people to work on the unpredictable, complex and dynamic problems of the future.

Together with the expectations and perceptions of the academic community, the functions of the higher education system have changed today. Today they are considered to be:

(a) Providing education and training within a structure integrati,ng research and instruction,

(b) Providing professional training,

(c) Carrying out research in abroad range of disciplines and training qualified people for all fields of employment,

(d) Playing a part in regional development and developing international contacts, and

(e) Fostering the intellectual and social development of society.

The importance of the above functions evidently varies from place to place and in time. So will the requirements for excellence change: so that it must be seen as intrinsically relative.

\section{Different Concepts of Excellence in International Context}

About 25 years ago the International Institute for Educational Planning organised a symposium on 'the qualitative aspects of educational planning with particular reference to developing countries'. The symposium dealt with the concept of quality both intensively and extensively and most of its deliberations are valid even today. The presentation here is based on them.

In dealing with the issue of excellence in the international context, it is important to make a distinction between product and process. Measured by any test, the higher education system of a developed country will be able to produce, in most cases, graduates of higher excellence on an average than a system of a developing country. Even within a country an elite institution of higher education may have an output of higher quality than other institutions, although its instructional processes may not be good. But if we consider the graduates of an ordinary institution of higher education in a developing country and compare them with their background and educational levels when they entered the system, we may find that their achievements have been significant and the institution has in fact done an excellent job, i.e. the instructional process could be judged as excellent.

\section{Recent Trends}

The resultant effect of this today, has been an ever growing state of political instability and vulnerability (so widespread especially in the Third World) with concomitant repercussions on education. Most of these upheavals have been a consequence of glaring socio-economic disparities within Third World countries with staggering proportion of landless rural families, spreading unemployment, increasing poverty and atrociously poor social and welfare services.

Educational development is today faced $\mathrm{v}$-ith the unleashing of new forces of production and reproduction of economic and social conditions. While the promise of policies and its practical performance mark this period, a new set of factors have direct implications on the development of education. Some of the most important are the growing debt problems of Third World countries; the pressure of technological advances and national development strategies vis-a-vis growing international (inter) dependencies manifesting in open class, communal and religious tensions within these countries. The confluence of all these forces has already begun to show ominous signs of a second crisis (after the Coombian Crisis) epitomized in a combination of, on the one hand, explosive growth of learning needs and on the other, a more pronounced stratification in the educational system.

Assuming that universal elementary education (UEE) successfully reaches the large mass of existing illiterate rural population in the third world, the trend in urban areas is now towards acquiring skills (vocational education). The expansion of vocational education is with the definite intention of providing intermediary services to the mushrooming manufacturing and consumer industries which are rapidly being set up as a consequence of liberal economic policies that are ushering in large scale foreign investment and their agenciesthe multinational corporations.

At the same time, entry to higher education is being steadily curtailed through a policy (deliberate?) to toughen recruitment standards. This has a two-pronged effect. First, it ensures a steady supply of semi-skilled labour force to the manufacturing industries and second, entry into higher education is increasingly being confined to the elite strata whose social class provides them with the prerogative of obtaining educational success as well as striving for higher educational ambitions. 
State educational policies are thus reinforcing a social stratification, quite sharply demarcated along class lines. In Ac 60s and 70s mere was still considerable scope for inter-class mobility through educational attainments. That is to say, the bottom most (and majority) section of the society in most third world countries the landless, the small farmers, the unskilled workers (who also form the bulk of the rapidly growing informal economy) are the targets for UEE and non-formal education; middle section, i.e. the lower and middle classes, for vocational education while the upper middle and the elite having the choice of, as well as access to higher education, both for learning as well as for a profession.

\section{Education Research In India}

The foregoing account of comparative education studies by researchers, other than professed comparative educators whose primary interests were pedagogic improvement and educational expansion, requires to be supplemented by work in formal comparative education and the work of social scientists who have interested themselves in education. Inter-regional intra- Indian variations and historical studies of developments in Indian education, which emerged from its British colonial origins, tended to lay some basis for comparative understanding of Indian education (Rudolph and Rudolph 1972) in which (a) the relationship of caste to education (Madan and Halbar 1972), and (b) education as political resource (Gould 1972), Of (c) university structure as is conveyed from its British background etc. (e.g. Rudolphand Rudolph 1972) are brought out. One major omission or lacuna in this entire corpus which persists even today is the overlooking of the widespread system of indigenous schooling, higher learning as well as professional education, which not only existed before British rule but persists even today. The manner in which a wide variety of skills-clerical, commercial/accounting, medical etc. are intermeshing and are caught between these and westernised formal education organised by the modem state is an aspect which is not paid much attention even though a very large number of trading and small business personnel, indigenous medical practitioners of Ayurveda as well as Unani medicine and the traditional classical learning in Sanskrit and Arabic and Persian as well as priestly training in pathshalas, maktabs, and madarasas are taught and nurtured there. They play important infrastructural roles in society and economy (Brass 1972) even if they might not be as overtly influential as, for instance, Buddhist clergy and medical menin Sri Lanka. They do exercise substantial ideological influence in preserving traditional family and religious orientations in the populace even as modernisation and westernisation proceed through 'modern' educational system (Brass1972)

The trends in research in cross-cultural psychology in India are not much different from the above. Even with distinct epistemological traditions in the field of psychology, nature of research in this century has been typically of the "western style." When western psychology "broke away" from philosophy to become science, the quest to use scientific method altered the very nature of the discipline. Western scholars looked for basic universal constructs which would stand the test of time and place, thereby denying history and culture its legitimate place in psychology. It is here where Indian psychology departed meta-theoretically from the western psychology and was renamed as "true psychology" or fndian Psychology. Indian thinkers refused to remove psyche from psychology as the "logy" of the salvaged part made little sense to them. They firmly believed that the individual behaviour can be understood only in relation to desh (place), kala (time) and patra (individual), emphasising the socio-cultural. embeddedness of human mind and behaviour the crux of Indian thought.

A final word about the epistemology and methodology of comparative education studies in India. In all research it is important to note who studies whom and how. Comparative education started with the developed and developing West. It studied parts of itself-as sociology did in social sciences generally. Then it studied the eastern countries--and what is now known as the South with different cultural origins and at different levels of power and technology, in fact, as the object of dominance. Thus, as in early anthropology, the dominated was also the object of study. Comparative education also tended to be subject to a teleology, a determinism: that there is a given direction of growth and development. Even when the object-India in this case-became the subject, studying itself, it has employed the tools and methodology applied by the North (West) to itself and to it. Again, the Indian scholar or the approach of Indian comparative education has not studied the North. It has not been marked, so far. by a distinct view or orientation it might take of the West. It has not been subject, making West an object of study. Finally, it has not so far rejected the teleology, the determinism of western comparative education.

This caveat could well be a false and futile criticism of, in fact, a different very legitimate situation, viz. that there is a universalism of science and so also the science of comparative education. In teleology, in the stages of development in education determined by this teleology, India like other Third World (or South) nations is only late or behind, and will develop along the same lines as the West (North) over time. If this view be correct, the caveat in the previous paragraph is invalid and false. And comparative education in India is only at an early and primitive stage of the most advanced comparative education of the West (North). It only requires to have more data and use more sophisticated techniques. But in a World Congress-and in a period when not just objectivity and modernity but also the deeper questions of the truth and validity of objectivity and modernity, or 
post-modern subjectivity, are being considered-one should think of not just technical sophistications in the direction of field-work, empirical or quantitative advances but also major changes of viewpoint about relationship between dominant and dominated, between the subject and the object, both inter- and intranationally. We need to consider not just development of such education as exists but also the reexamining of existing and considering of alternative educational systems and relationships. Comparative education in India too, if not elsewhere, has not yet faced up to this question which has emerged on the threshold of a new millennium the third millennium A.D.

\section{Conclusion}

The educational process the world over is in a deep state of crisis. The so-called developed countries are not entirely free from this crisis either. They can scarcely provide a model to emulate. The countries in the Third World have already paid a heavy price for having uncritically taken the dominant ideology of development strategies for granted. There have been structural constraints which have thwarted development of education compatible to the indigenous needs of Third World countries, The experiences of most Latin American countries despite or high growth rates and industrialization, must stand as a warning signal to other Third World countries which are now emulating the Latin American model of economic development Most of these countries by the eighties, suffered large external deficits, uncontrollable inflation, economic and political destabilization and worst of all, a pauperization. and destitution of its middle and lower strata of society.

The educational structure of these countries was organized on lines as described in the figure above. With the economic crises, foreign capital fled from these countries and multinational companies shifted their operations to other, more lucrative areas. The bulk of the labour force employed in these industries, products of vocational training, were left unemployed with little use of their skills that were once acclaimed as hi-tech. Latin American economies, on their own, were unable to absorb this labour force into productive employment due to the lack of indigenous infrastructures.

Needless to say, that it is the 'process of democratization' of education in Cuba for instance, that has no doubt enabled it to overcome its basic problems of universal, primary and vocational education. Unlike the features of educational expansion under U.S. funding, the combating of mass illiteracy has been a feature of regimes seeking to widen educational access and public awareness. Cuba has by most criteria, sustained itself both economically and educationally since 1959 . The limited scope of this paper does not allow me to go into details of this significant experience.

In spite of the recent political reverses on the student front, the experience of the Chinese educational development points to the balance between the growing awareness of Chinese educational policies as a means of continuing the revolution through class struggle, political education and consciousness raising, and education as a means of supplying skilled human resources to increase production. The goals and objectives for the Chinese educational policy makers was not to make education as an end in itself but as a means towards modernizing and at the same time pursuing a revolutionizing policy of social change that imbibed the best of human resource development as also making them meaningful agents of social change. With regard to non-formal education in China, it has been the most innovative with the ultimate aim of reducing distinctions between the formal and non-formal streams as China's countryside becomes increasingly industrialized. If many Third World countries today are locked into a dependency relationship with powerful industrial economies with educational and cultural relations reflecting this relationship, then the experience of countries like Cuba, Nicaragua, Vietnam and China stand as examples demonstrating the success of development through a tactful policy of self-reliance and interdependence.

Any serious attempt to come to terms with the international forces which impingeon development of education must examine the role of corporate interest and the underlying ideology of economic growth. There is, however, an urgent need to look at practical strategies to curb vested interests and provide education to the masses for awareness of their environment and learning to be. No piece-meal attempt to import strategies can resolve present contradictions as obtained in the national economies of the Third World. Elegant theories are never a substitute to political will and practical action. The attempt in this paper has been to uncover the historical and economic forces which have had a direct bearing on the process of educational development within history and society.

[1]. Jandhyala B.G.Tilak (2010) -

\section{References:}

Education, Society and Development

[2]. Lester D.Crow and Alice Crow (2008) - "Child Development and Adjustment"

[3]. Dr.S.Arulsamy (2011) - "Philosophical and Sociological Perspectives in Education".

[4]. S. Narayana Rao (2009) - "Counseling and Guidance"

[5]. Shashi Prabha Sharma (2008) - "Basic Principles of Education" 